\title{
Simultaneous Profiling of DNA Mutation and Methylation by Melting Analysis Using Magnetoresistive Biosensor Array
}

Rizzi, Giovanni; Lee, Jung-Rok; Dahl, Christina; Guldberg, Per; Dufva, Martin; Wang, Shan X.; Hansen, Mikkel Fougt

Published in:
A C S Nano

Link to article, DOI:

10.1021/acsnano.7b03053

Publication date:

2017

Document Version

Peer reviewed version

Link back to DTU Orbit

Citation (APA):

Rizzi, G., Lee, J-R., Dahl, C., Guldberg, P., Dufva, M., Wang, S. X., \& Hansen, M. F. (2017). Simultaneous Profiling of DNA Mutation and Methylation by Melting Analysis Using Magnetoresistive Biosensor Array. A C S Nano, 11(9), 8864-8870. https://doi.org/10.1021/acsnano.7b03053

\section{General rights}

Copyright and moral rights for the publications made accessible in the public portal are retained by the authors and/or other copyright owners and it is a condition of accessing publications that users recognise and abide by the legal requirements associated with these rights.

- Users may download and print one copy of any publication from the public portal for the purpose of private study or research.

- You may not further distribute the material or use it for any profit-making activity or commercial gain

- You may freely distribute the URL identifying the publication in the public portal 


\title{
Simultaneous Profiling of DNA Mutation and
}

\section{Methylation by Melting Analysis Using}

\section{Magnetoresistive Biosensor Array}

\author{
Giovanni Rizzi $i^{\dagger}$, Jung-Rok Lee ${ }^{\dot{t}, \xi}$, Christina Dahl ${ }^{\perp}$, Per Guldberg $^{\perp}$, Martin Dufva $^{\dagger}$, \\ Shan X. Wang *s, ", Mikkel F. Hansen*' \\ ${ }^{\dagger}$ Department of Micro- and Nanotechnology DTU Nanotech, Building 345B, Technical \\ University of Denmark, Kongens Lyngby, DK 2800, Denmark \\ "Division of Mechanical and Biomedical Engineering, ELTEC College of Engineering, Ewha \\ Womans University, Seoul 03760, South Korea \\ ${ }^{\S}$ Department of Materials Science and Engineering, Stanford University, Stanford, CA 93405, \\ USA \\ ${ }^{\perp}$ Danish Cancer Society Research Center, Copenhagen, DK 2100, Denmark \\ " Department of Electrical Engineering, Stanford University, Stanford, CA 93405, USA
}




\begin{abstract}
Epigenetic modifications, in particular DNA methylation, are gaining increasing interest as complementary information to DNA mutations for cancer diagnostics and prognostics. We introduce a method to simultaneously profile DNA mutation and methylation events for an array of sites with single site specificity. Genomic (mutation) or bisulphite-treated (methylation) DNA is amplified using non-discriminatory primers, and the amplicons are then hybridized to a giant magnetoresistive (GMR) biosensor array followed by melting curve measurements. The GMR biosensor platform offers scalable multiplexed detection of DNA hybridization, which is insensitive to temperature. The melting curve approach further enhances the assay specificity and tolerance to variations in probe length. We demonstrate the utility of this method by simultaneously profiling five mutation and four methylation sites in human melanoma cell lines. The method correctly identified all mutation and methylation events and further provided quantitative assessment of methylation density validated by bisulphite pyrosequencing.
\end{abstract}

KEYWORDS: methylation, mutation, DNA array, GMR biosensor, melanoma, melting curve. 
Cancer is a cellular disease caused by the stepwise accumulation of genetic and epigenetic alterations. ${ }^{1,2}$ Extensive sequencing efforts have identified recurrent genetic mutations that are useful as genetic biomarkers for assessing risk of developing cancer, classifying disease subtypes, predicting response to treatment, and monitoring efficacy of treatment. DNA methylation causes epigenetic silencing of tumor suppressor genes and is studied for both its direct implication in oncogenesis and for its utility as cancer biomarker. ${ }^{3-5}$ In bladder and colon cancer, the combination of genetic and epigenetic analyses has been proven to have a higher diagnostic value than either of the two approaches applied separately. ${ }^{6,7}$ However, compared to mutation genotyping, methylation profiling is not a yes-no result. Many promoter regions contain $\mathrm{CpG}$ islands, i.e. clusters of multiple $\mathrm{CpG}$ dinucleotides (the most common methylation site), and gene silencing mechanisms driven by promoter methylation are generally sensitive to the overall density of methylated sites. Finally, the methylation density may vary between alleles and cells within a single tumor, resulting in a heterogeneous pattern. ${ }^{4,8,9}$

A variety of techniques have been developed to detect single point mutations in DNA based on amplification, ${ }^{10,11}$ probe hybridization, ${ }^{12}$ enzymatic digestion, ${ }^{11}$ gel electrophoresis, ${ }^{13}$ or sequencing. ${ }^{14}$ DNA methylation information is lost during polymerase chain reaction (PCR) amplification, and DNA hybridization is insensitive to the methylation status of the target region. Therefore, a methylation sensitive pretreatment of the DNA has to be employed. The main DNA methylation analysis techniques are based on methylation sensitive enzymatic digestion, affinity enrichment using antibodies specific for methylated cytosine or bisulphite conversion of unmethylated cytosine into uracil (reviewed by Laird $^{9}$ and Plongthongkum et al. ${ }^{8}$ ). Bisulphite conversion is most widely used since a methylation event is converted into a single base alteration $(\mathrm{C} / \mathrm{T})$ that can be detected with techniques derived from mutation detection including 
sequencing array hybridization, methylation sensitive $\mathrm{PCR},{ }^{9}$ and methylation sensitive melting curve analysis. ${ }^{15,16}$ Sequencing of bisulphite-converted DNA quantifies the methylation status and allows for comparison of data from different sequencing runs and batches, but it is costly and time consuming. ${ }^{8}$ Amplification-based techniques are limited in multiplexing by the number of available fluorophores and the number of channels in the thermocycler. Similarly, meltingbased techniques as high resolution melting (HRM) have limited multiplexing capabilities and are only weakly sensitive to A-T and C-G single base substitutions. Array-based methods, such as the Illumina BeadChip (Illumina Inc., San Diego, CA), offer a highly multiplexed site-specific assay. However, after bisulphite conversion and amplification of the template, DNA products comprise mostly three bases (guanine, adenine, and thymine plus residues of methylated cytosine). This reduced sequence complexity makes design of probes for end-point detection complicated and the decreased sequence variation reduces specificity. ${ }^{9}$

Our work aims to perform methylation and mutation profiling simultaneously in a scalable chip platform that offers highly specific and quantitative DNA methylation and mutation data on a compact, easy-to-use, and potentially low-cost platform. Our approach is based on hybridization of magnetically labelled target DNA to DNA probes tethered to the surface of a GMR biosensor array (Figure 1). The magnetic detection approach has been previously demonstrated for DNA detection ${ }^{17-19}$ as well as immunoassays. ${ }^{20}$ To increase the specificity of the DNA hybridization assay, we employed melting curve measurements of the surface-tethered DNA hybrids. ${ }^{21}$ This avoids conventional assay condition optimization since the target-probe hybrids are exposed to continuously increasing stringency during melting curve measurement. ${ }^{22}$ Melting curves for surface-tethered DNA probes have been also measured using fluorescence ${ }^{23}$ and surface plasmon resonance. ${ }^{24,25}$ Compared to these methods, the GMR biosensors offer high 
sensitivity, no dependence on temperature and are insensitive to the sample matrix as virtually all biological material is non-magnetic. ${ }^{20,26}$

Using our technique, we analyzed melanoma cell lines with known genetic and epigenetic alterations. ${ }^{27,28}$ More specifically, we investigated mutations in $N R A S$ and $B R A F$, which are found in $15-25 \%$ and $50-70 \%$ of melanomas, respectively. ${ }^{29}$ In addition, we quantitatively measured the methylation status of the promoter regions of the genes encoding retinoic acid receptor $\beta(R A R B)$ and the receptor tyrosine kinase KIT $(K I T)$, which are targeted by hypermethylation in $20-70 \%$ and $25-40 \%$ of melanomas, respectively. ${ }^{28,30,31}$

\section{RESULTS AND DISCUSSION}

\section{DNA Mutation analysis}

To detect DNA mutations, we PCR amplified the genomic regions of interest using nondiscriminatory primers. The PCR products were then magnetically labeled using biotinylated primers and streptavidin-coated magnetic nanoparticles (MNPs). After magnetic column separation and denaturation of the double-stranded PCR products, ssDNA conjugated to MNPs (MNP-ssDNA) was introduced to the GMR biosensor array where multiple DNA probes were separately tethered to the surface of each sensor. ${ }^{19}$ Upon hybridization of the injected MNPssDNA to surface-tethered complementary probes, GMR biosensors produced changes in sensor magnetoresistive ratio $(\triangle M R)$ in proportion to the bound MNPs. ${ }^{32}$ To genotype a mutation, we employed a set of two probes complementary to the wild type (WT) and mutant type (MT) sequences of the sample (supplementary information Tabel S1). During hybridization at low stringency, amplicons hybridized to both WT and MT probes with similar affinity. To obtain single base specificity, stringent washing is typically used after hybridization in DNA microarray. To achieve a more flexible system for detection of single-base mutations, we 
challenged the hybrids by increasing the temperature and continuously measuring DNA melting simultaneously for all probes on the GMR biosensor array (Figure 1).

Figure 2a shows real-time monitoring of $\triangle M R$ during hybridization ( 1 hour at $37{ }^{\circ} \mathrm{C}$ ) of a known WT sample to probes with a perfect match (WT) or a single-base mismatch (MT) for the $B R A F$ c. $1391 \mathrm{G}>\mathrm{A}$ mutation. In addition, a biotinylated DNA probe was used as positive reference and a DNA probe with an unspecific sequence was used as negative reference. After 1 hour of hybridization, the MT probe gave a slightly higher $\triangle M R$ signal than the WT probe, indicating that low-stringency hybridization was insufficient to genotype the WT sample. The positive reference signal reached a higher level than the hybridization probes due to the faster kinetics of the biotin-streptavidin interaction compared to hybridization. After hybridization, the unbound sample was removed by a low-temperature wash at low stringency. Then, the temperature of the sensor was ramped at constant rate from $20{ }^{\circ} \mathrm{C}$ until all DNA hybrids melted at $65^{\circ} \mathrm{C}$ (Figure $\left.2 \mathrm{a}\right)$. The signal $(\triangle M R)$ from GMR biosensors was corrected for its temperature dependence during ramping using the sensor resistance $(R)$, which is linearly related to the sensor temperature.

Figure $2 \mathrm{~b}$ shows the melting curve of WT $B R A F$ amplicons hybridized to WT and MT probes for the c. $1391 \mathrm{G}>\mathrm{A}$ mutation. Here, the $\Delta M R$ signal was normalized by the initial signal at $T=20$ ${ }^{\circ} \mathrm{C}$. We defined the melting temperature $T_{\mathrm{m}}$ as the temperature at which the signal $(\Delta M R)$ dropped to the half of its initial signal (at $20^{\circ} \mathrm{C}$ ). Each melting experiment was repeated with two identical GMR biosensor chips. Three sensors were functionalized with each probe, thus generating up to six identical melting curves for each probe. The obtained melting curves were found to be highly reproducible - both from sensor to sensor and from chip to chip. The hybrids of the target DNA with WT and MT probes in Figure $2 \mathrm{~b}$ showed melting temperatures of 
$T_{\mathrm{m}}(\mathrm{WT})=43.0(7){ }^{\circ} \mathrm{C}$ and $T_{\mathrm{m}}(\mathrm{MT})=38.9(7){ }^{\circ} \mathrm{C}$, respectively, where the numbers in parentheses are standard deviations of $T_{\mathrm{m}}$ on the last digit $(n \geq 4)$. We defined the melting temperature difference, $\Delta T_{\mathrm{m}}$, as the difference between the melting temperature from the MT probe and that from the WT probe, $\Delta T_{\mathrm{m}}=T_{\mathrm{m}}(\mathrm{MT})-T_{\mathrm{m}}(\mathrm{WT})$. Thus, $\Delta T_{\mathrm{m}}<0$ indicates a higher complementarity of the target to the WT probe than the MT probe, and hence that the target is WT. The obtained value $\Delta T_{\mathrm{m}}=-4.0(3){ }^{\circ} \mathrm{C}$ is in agreement with the expectation for a single base mismatch between the WT target and MT probe using a nearest neighbor calculation. ${ }^{33} \mathrm{We}$ also note that the lower standard deviation of $\Delta T_{\mathrm{m}}$ compared to $T_{\mathrm{m}}$ indicates that differences in melting temperatures were more reproducible than their absolute values.

Figure 2c shows melting curves measured for a cell line heterozygous for the $B R A F$ c. $1391 \mathrm{G}>$ A mutation. ${ }^{27}$ The melting curves from WT and MT probes were found to overlap each other, resulting in $\Delta T_{\mathrm{m}}=-0.6(4){ }^{\circ} \mathrm{C}$ because the heterozygous sample contains both MT and WT targets, which hybridize to both WT and MT probes. The resulting melting curves from WT and MT probes were both given by the contribution of low- $T_{\mathrm{m}}$ and high- $T_{\mathrm{m}}$ DNA hybrids. Therefore, the melting curves overlapped and presented a lower slope.

\section{DNA methylation analysis}

We applied a similar detection scheme to analyze the methylation state of specific regions of the target. We employed bisulphite treatment of the genomic DNA (Figure 3a) to convert a methylation event into a single base substitution $(\mathrm{C}>\mathrm{T})$. After bisulphite conversion, we amplified the gene promoter region of interest by non-discriminatory PCR.

Figures $3 \mathrm{~b}$ and $\mathrm{c}$ show melting curves to estimate methylation status of the KIT promoter (site p1) of hypermethylated (EST045) and wild-type (EST164) cell line. ${ }^{28}$ The amplicons were 
hybridized to probes complementary to unmethylated (U) or methylated (M) target DNA. Melting curves were measured as described previously. Here, $\Delta T_{\mathrm{m}}$ was defined as the melting temperature of the $\mathrm{M}$ probe minus that of the $\mathrm{U}$ probe, $\Delta T_{\mathrm{m}}=T_{\mathrm{m}}(\mathrm{M})-T_{\mathrm{m}}(\mathrm{U})$. Thus, a negative $\Delta \mathrm{T}_{\mathrm{m}}$ indicates a higher complementarity of the target to the $\mathrm{U}$ probe and a lower degree of methylation. The $\sim 20$ bp region of the KIT promoter investigated includes three CpG sites that can be methylated (sequences in supplementary information Table S1), and thus we expect higher $\Delta T_{\mathrm{m}}$ than for single base substitution. For the hyper-methylated cell line in Figure $3 \mathrm{~b}$, we found $\Delta T_{\mathrm{m}}=8.1(1)^{\circ} \mathrm{C}$, confirming the hyper-methylation status of the KIT promoter, whereas we found $\Delta T_{\mathrm{m}}=-11.7(7){ }^{\circ} \mathrm{C}$ for the WT cell line in Figure $3 \mathrm{c}$, indicating the unmethylated status.

\section{Multiplex DNA profiling of melanoma cell lines}

The GMR biosensor array comprises of 64 individual sensors that can be individually functionalized with amino-modified DNA probes. Using the mutation and methylation detection techniques described above, we simultaneously probed three mutation sites in $B R A F$, two mutation sites in NRAS, two methylation sites in the KIT promoter, and two methylation sites in the $R A R B$ promoter in triplicate. We performed mutation and methylation profiling of seven melanoma cell lines. For each cell line, the targeted regions of $B R A F$ and of $N R A S$ were amplified by non- discriminatory PCR. Also, the promoter regions of KIT and RARB were amplified by non-discriminatory PCR after bisulphite conversion. After magnetic labeling, a mixture of all amplicons from a cell line was injected over the sensor surface. For each cell line, melting curve profiling was repeated with two nominally identical GMR biosensor arrays. The melting curves were analyzed in terms of melting temperatures, and we determined $\Delta T_{\mathrm{m}}$ for all investigated mutations and methylation. 
Figure 4a shows the $\Delta T_{\mathrm{m}}$ values measured for the $B R A F$ c. $1391 \mathrm{G}>\mathrm{A}$ mutation for all cell lines (other mutation sites are shown in supplementary Figure $\mathrm{S} 1$ ). Six cell lines showed $\Delta T_{\mathrm{m}}$ values around $\Delta T_{\mathrm{m}}=-4{ }^{\circ} \mathrm{C}$, indicating a homozygous WT sequence. EST164 is known to be the only cell line with a heterozygous mutation in this site, ${ }^{27}$ showing $\Delta T_{\mathrm{m}}=-0.5(4){ }^{\circ} \mathrm{C}$, which is significantly different from the other cell lines.

The $\Delta T_{\mathrm{m}}$ values measured for all investigated mutations for each cell line are displayed in the heat map of Figure $4 \mathrm{~b}$. Classifying WT $\left(\Delta T_{\mathrm{m}}<-2{ }^{\circ} \mathrm{C}\right)$, heterozygous MT $\left(-2{ }^{\circ} \mathrm{C}<\Delta T_{\mathrm{m}}<2{ }^{\circ} \mathrm{C}\right)$, and homozygous $\mathrm{MT}\left(\Delta \mathrm{T}_{\mathrm{m}}>2{ }^{\circ} \mathrm{C}\right)$ resulted in the mutation map presented in Figure 4c. All mutations identified in the cell lines were consistent with previous genotyping data. ${ }^{27}$ For the $N R A S$ c.182 $\mathrm{A}>\mathrm{T}$ mutation in the cell line EST045, we measured $\Delta T_{\mathrm{m}}=-0.2(4){ }^{\circ} \mathrm{C}$, genotyping the cell line as heterozygous for this mutation; however, the cell line is known to be heterozygous for an $\mathrm{A}>\mathrm{G}$ substitution in that location (see supplementary Figure S2). As an MT probe targeting an $\mathrm{A}>\mathrm{T}$ mutation was employed, both the $\mathrm{WT}$ and $\mathrm{MT}$ probes were similarly mismatched to the target, resulting in $\Delta T_{\mathrm{m}}$ close to zero. The absolute values of $T_{\mathrm{m}}$ in supplementary Figure S2 were comparable to the other investigated mismatched probes confirming the mismatch of the target to both the WT and MT probes. Therefore, an unknown mutation can be detected by a lower $T_{\mathrm{m}}$ from the WT probe, but probes targeting all possible mutations should be included in the assay to perform accurate genotyping.

\section{DNA methylation density}

Methylation profiling differs substantially from genotyping since the methylation status of each $\mathrm{CpG}$ site in the promoter region varies between alleles and within a cell population. Therefore, it requires a different data analysis in terms of methylated fraction of the sample 
DNA. We measured melting curves using surface-tethered probes targeting two locations of the $K I T$ promoter and two locations of the $R A R B$ promoter. The targeted sequences contain one to four $\mathrm{CpG}$ sites. Combining multiple investigated sites with the intrinsic variation of the methylation pattern, we obtained a continuous variation of $\Delta T_{\mathrm{m}}$ for the analyzed cell lines. Figure 5a shows the measured $\Delta T_{\mathrm{m}}$ values for all cell lines. Here, higher $\Delta T_{\mathrm{m}}$ in yellow or red indicates higher affinity of the sample to the $\mathrm{M}$ probe, i.e., a hypermethylation event. The complex $\Delta T_{\mathrm{m}}$ pattern is a direct consequence of the intrinsic methylation variation.

The methylation density was assessed independently by pyrosequencing of the bisulphiteconverted DNA. To each target sequence corresponding to the probes, we calculated methylation density depending on both the fraction of methylated sample and the number (1 to 4$)$ of methylated $\mathrm{CpG}$ sites in the region targeted by the probe. Figures $5 \mathrm{~b}$ and $5 \mathrm{c}$ show $\Delta T_{\mathrm{m}}$ measured using the GMR biosensor versus the methylation density obtained by pyrosequencing for the KIT $\mathrm{p} 1$ and $\mathrm{p} 2$ probe locations and the $R A R B \mathrm{p} 1$ and $\mathrm{p} 2$ probe locations, respectively. In these plots, each point corresponds to one of the measured cell lines. There is an evident linear correlation between $\Delta T_{\mathrm{m}}$ and the methylation density $\left(\mathrm{R}^{2}>0.94\right.$ for all probe locations, results of linear regression are given in supplementary Table $\mathrm{S} 4)$. For the KIT $\mathrm{p} 1$ and $\mathrm{p} 2$ probes, the slopes are comparable $\left(\sim 0.22{ }^{\circ} \mathrm{C} / \%\right.$, Figure $\left.5 \mathrm{~b}\right)$, whereas for the $R A R B$ probes, the slopes for the $\mathrm{p} 1$ and $\mathrm{p} 2$ probes differ significantly $\left(\mathrm{p} 1: 0.076(5){ }^{\circ} \mathrm{C} / \%, \mathrm{p} 2: 0.22(2){ }^{\circ} \mathrm{C} / \%\right)$. The slope for the $\mathrm{p} 2$ probe was three times that for the $\mathrm{p} 1$ probe because the $\mathrm{p} 2$ probe covers three $\mathrm{CpG}$ sites whereas the $\mathrm{p} 1$ probe only covers one $\mathrm{CpG}$ site. Nevertheless, three methylation sites allowed for a more complex pattern of methylation sites and thus the $R A R B \mathrm{p} 2$ probe showed a broader spread of data around the best linear fit. The probes can be tailored to sacrifice linearity to favor higher values of $\Delta T_{\mathrm{m}}$. 
These results demonstrate the application of temperature melting on a GMR biosensor as a semi-quantitative method for profiling methylation density. High-throughput profiling of genome wide methylation can be performed with single-base resolution using array-based methods like Illumina BeadChips but the specificity of such arrays is limited by lower sequence variability of bisulphite converted DNA. ${ }^{8,9}$ A quantification of the overall methylation density of a gene promoter can be obtained with methylation-specific melting curve analysis. ${ }^{15,16}$ Here, we combined the throughput and scalability of arrays with the specificity and flexibility of melting curve analysis. The obtained quantitative profiling was equivalent to the results of pyrosequencing.

\section{CONCLUSION}

We have presented an approach for simultaneous DNA mutation and methylation profiling. Our method combines the widespread DNA microarray techniques for both mutation and methylation analysis in a single platform. Melting curves measurements are used to increase the specificity of mutation detection. For methylation detection, the melting curve quantifies the methylation state at a level equivalent to pyrosequencing. The same technique could potentially be employed on a variety of other platforms capable of masuring DNA hybridization vs. temperature.

The GMR biosensor platform has a low cross-sensitivity to temperature and provides a sensitive readout. Although it does not offer the extreme throughput as advanced bead microarray systems (e.g.: Illumina), in its present format, the GMR biosensor platform can be used for the simultaneous triplicate investigation of about 20 mutation and methylation sites. 
Nevertheless, the GMR biosensor array has a modular design that can be scaled to include up to thousands of biosensors. $^{32}$

\section{METHODS}

Cells and reagents. Melanoma cell lines for this study were obtained from The European Searchable Tumour Line Database (ESTDAB: http://www. ebi.ac.uk/ipd/estdab) and were maintained in RPMI-1640 medium containing $10 \% \mathrm{FBS}$ and antibiotics at $37{ }^{\circ} \mathrm{C}$ and $5 \% \mathrm{CO}_{2}$. The PCR primers for this study have been modified from Dahl et al. ${ }^{27,28}$ and were obtained from DNA Technology A/S, Denmark. The sequences can be found in the supplementary material Table S2. The amine modified DNA probes (sequences in supplementary material Table S1) were matched for melting temperature calculated with nearest-neighbor model. ${ }^{33}$ The probes were obtained from DNA Technology A/S. The other reagents: poly(ethylene-alt-maleic anhydride) (Sigma Aldrich), poly(allylamine hydrochloride) (Polyscience), distilled water (Invitrogen), 1-Ethyl-3-(3-dimethylaminopropyl)-carbodiimide EDC (Sigma Aldrich), Nhydroxysuccinimide NHS (Sigma Aldrich)1\% bovine serum albumin BSA (Sigma Aldrich), phosphate buffered saline PBS (Gibco), distilled water (Invitrogen), Tween 20 (Sigma Aldrich), Urea (Fisher Scientific), 20× saline sodium citrate SSC (Invitrogen), mineral oil (Sigma Aldrich), MNPs Streptavidin MicroBeads (Miltenyi), magnetic separation columns $\mu$ Columns (Miltenyi).

DNA extraction and bisulphite treatment. Genomic DNA was isolated using the Qiagen AllPrep DNA/RNA/Protein Mini kit (Qiagen GmbH, Hilden, Germany) and quantified using a NanoDrop ND-1000 spectrophotometer (NanoDrop Technologies, Wilmington, DE). Bisulphite 
conversion of DNA (500 ng) was carried out using the EZ DNA Methylation-Gold ${ }^{\mathrm{TM}}$ Kit (Zymo Research, Irvine, CA) according to the manufacturer's protocol.

PCR amplification. Prior to the GMR biosensor assay, PCR was performed using a Veriti ${ }^{\mathrm{TM}}$ 96Well Thermal Cycler (Applied Biosystems) and TEMPase Hot Start Polymerase (VWR). All amplifications were initiated with enzyme activation and DNA denaturation at $95{ }^{\circ} \mathrm{C}$ for 15 minutes, 40 cycles of $95{ }^{\circ} \mathrm{C}$ for 30 seconds, $56^{\circ} \mathrm{C}$ for 30 seconds and $72{ }^{\circ} \mathrm{C}$ for 30 seconds, followed by a final incubation at $72{ }^{\circ} \mathrm{C}$ for 10 minutes. All primer sequences used are listed in the supplementary material Table S2.

Magnetic labelling. Products from PCR amplification of each cell line were processed as described by Rizzi et al. ${ }^{19}$ to obtain ss-DNA target conjugated with MNPs. Briefly, for each amplified region, $10 \mu \mathrm{L}$ of PCR products were mixed with $10 \mu \mathrm{L}$ of stock solution of streptavidin-coated MNPs (MACS Streptavidin Microbeads, cat: 130-048-102, Miltenyi Biotec Norden AB, Lund, Sweden) and incubated for 30 min at $37^{\circ} \mathrm{C}$. A magnetic separation column $(\mu$ column, Miltenyi Biotec Norden AB, Lund, Sweden) was prepared by washing with $1 \mathrm{~mL}$ of $1 \%$ Tween 20 and $1 \mathrm{~mL}$ of $0.1 \%$ BSA containing $0.05 \%$ Tween 20 , sequentially. After the conjugation with magnetic particles, the five PCR products were mixed and added to the column under an applied magnetic field for separation. While the target DNA-bead complexes were trapped in the column, the reverse strands were denatured and removed by adding $2 \mathrm{~mL}$ of $6 \mathrm{M}$ Urea solution at $75{ }^{\circ} \mathrm{C}$. Then, the applied magnetic field was removed, and the conjugated complexes were eluted with $100 \mu \mathrm{L}$ of $2 \times \mathrm{SSC}$ buffer.

Sensor preparation. The GMR biosensor chip with an array of $8 \times 8$ sensors was fabricated as previously described. ${ }^{34}$ The chip surface was chemically activated following Kim et al. ${ }^{35}$ Briefly, 
the chip was sequentially washed with acetone, methanol, and isopropanol. After cleaned with oxygen plasma, the chip was treated with poly(ethylene-alt-maleic anhydride) for 5 min. Then, the chip was washed with distilled water, and baked at $110^{\circ} \mathrm{C}$ for 1 hour using a hot plate. After treatement with poly(allylamine hydrochloride) for $5 \mathrm{~min}$, the chip was washed with the distilled water, and activated with a mixture of NHS and EDC for 1 hour. After the chip was washed again with distilled water, a robotic arrayer (sciFlexarrayer, Scienion) was used to print the amino-modified DNA probes on different sensors (Supplementary Table S2). Each DNA probe was dissolved in $3 \times \mathrm{SSC}$ buffer at $20 \mu \mathrm{M}$, and was used for printing in triplicate. Four sensors on the same chip were functionalized with biotinylated DNAs as positive references, and another set of four sensors was functionalized with DNA non-complementary to any of the PCR amplified regions as negative references. The chip was stored at room temperature until use.

Data acquisition for temperature calibration. Prior to the assay, the thermal resistivity of each GMR sensor was characterized for temperature calibration. The temperature coefficient for each chip was obtained by linear fitting to resistance measurements at $20,30,40,50$ and $60{ }^{\circ} \mathrm{C}$. The temperature coefficient was then used to trace the instantaneous temperature of each sensor.

GMR biosensor assay. The measurement setup described previously ${ }^{26,36}$ was employed to measure the response of GMR sensor to MNPs. The temperature of the GMR chips was controlled by means of a Peltier element coupled to the chip. The Peltier element was driven by a LFI3751 control unit (Wavelength Electronics, USA) with a Pt1000 thermoresistor (Supplementary Information Figure S4). First, the chip was washed with $3 \mathrm{~mL}$ of $0.1 \%$ bovine serum albumin (BSA, Sigma Aldrich) and 0.05\% Tween20 (Sigma Aldrich). The chip was then blocked with $100 \mu \mathrm{L}$ of $1 \%$ BSA for $1 \mathrm{~h}$ in a shaker. After blocking, the chip was washed with 3 $\mathrm{mL}$ of $0.1 \% \mathrm{BSA}$ and $0.05 \%$ Tween 20 , followed by washing with $3 \mathrm{~mL}$ of distilled water. Prior 
to sample injection, a base line signal measurement was performed for 2 min at $37{ }^{\circ} \mathrm{C}$. After sample injection, the DNA hybridization signals from different sensors were measured for $1 \mathrm{~h}$ at $37{ }^{\circ} \mathrm{C}$. Then, the temperature was lowered to $20{ }^{\circ} \mathrm{C}$ to inhibit further binding of the sample and stabilize DNA hybrids. The chip was washed five times with $100 \mu \mathrm{L}$ of $0.05 \times$ SSC to remove unbound sample. $150 \mu \mathrm{L}$ of $0.05 \times \mathrm{SSC}$ were left in the reaction well and covered with $50 \mu \mathrm{L}$ of mineral oil to prevent evaporation. Melting curves for all the probes were measured while temperature was ramped from $20{ }^{\circ} \mathrm{C}$ to $65^{\circ} \mathrm{C}$ at $0.05^{\circ} \mathrm{C} / \mathrm{s}$. The temperature was then swept back to $20^{\circ} \mathrm{C}$ to obtain temperature reference signals.

Data processing. The MNPs are detected as a variation of the magnetoresistivity $(\Delta M R)$ of the GMR sensors. The temperature coefficients of $\Delta M R$ were calculated for each sensor as in Hall et al. ${ }^{26}$ using the temperature reference signals. It was necessary to use a $5^{\text {th }}$ order polynomial to account for non-linear temperature dependency at high temperature (Supplementary Information Figure S5) . After temperature correction, the melting curves measured between $20{ }^{\circ} \mathrm{C}$ to $65{ }^{\circ} \mathrm{C}$ were normalized by their initial value at $20^{\circ} \mathrm{C}$. The melting temperature $T_{\mathrm{m}}$ was defined as the temperature at which the normalized signal is 0.5 . To calculate $T_{\mathrm{m}}$, a first order polynomial was fitted to the melting curve in the region of interest. Each mutation (methylation) site was genotyped using two probes. $\Delta T_{\mathrm{m}}$ was defined as the difference between $T_{\mathrm{m}}$ measured for the probe complementary to the mutated (methylated) sequence minus $T_{\mathrm{m}}$ measured for the probe complementary to the Wild Type (un-methylated) sequence.

Pyrosequencing. The methylation status of the RARB and KIT promoter regions was analyzed by pyrosequencing using the PyroMark Q24 platform (Qiagen) and subsequent data analysis using the PyroMark Q24 software. Primer sequences are listed in Supplementary Table S3. DNA enzymatically methylated in vitro (CpGenome Universal Methylated DNA; Millipore) and 
unmethylated DNA prepared by whole genome amplification (WGA; GenomePlex, SigmaAldrich) was used as methylation-positive and -negative controls, respectively.

1

2

3

4

5

7

8

9

10

11

12

13

14

15

16

17

18

19

20

21

22

23

24

25

26

27

28

29

30

31

32

33

34

35

36

37

38

39

40

41

42

43

44

45

46

47

48

49

50

51

52

53

54

55

56

57

58

59

60 


\section{FIGURES}

Figure 1. Schematic protocol for the detection of magnetically labelled DNA using GMR biosensors: (I) After denaturation of the reverse strand and labeling, PCR products are injected into the reaction well over the chip. The DNA labeled with MNPs hybridizes to complementary surface-tethered probes for 1 hour at $37^{\circ} \mathrm{C}$. (II) The DNA is hybridized to the sensor surface and unbound sample is removed by washing. (III) The temperature is swept from $20{ }^{\circ} \mathrm{C}$ to $65^{\circ} \mathrm{C}$ to measure the melting temperature, $T_{\mathrm{m}}$.

Figure 2. (a) Time series of the signal $(\triangle M R)$ from GMR biosensors functionalized with positive and negative references, wild type (WT) and mutant type (MT) probes for the $B R A F \mathrm{c} .1391 \mathrm{G}>\mathrm{A}$ mutation. Each line corresponds to up to three sensors functionalized with the same probe. The measurement was performed with PCR products from EST045 cell line that is WT for the investigated mutation. The sample was injected at $t=2 \mathrm{~min}$. After $60 \mathrm{~min}$ hybridization at $37^{\circ} \mathrm{C}$, the chip was washed and the temperature was ramped from $20{ }^{\circ} \mathrm{C}$ to $65{ }^{\circ} \mathrm{C}$ while measuring the melting curves. (b) and (c) show melting curves from WT (green) and mutant type MT (red) probes targeting $B R A F$ c. $1391 \mathrm{G}>\mathrm{A}$ mutation obtained for the indicated cell lines, where the EST045 and EST164 cell lines were wild type and heterozygous mutant, respectively. Signals were normalized by the initial signal at $T=20^{\circ} \mathrm{C}$. The melting temperature $T_{\mathrm{m}}$ is defined as the temperatures at which the normalized curves cross $0.5 . \Delta T_{\mathrm{m}}$ is the difference in melting temperature between the MT and WT probes. The numbers in parentheses are standard deviations on the last significant digit $(n=4-6)$. Graphs of the first derivative of the melting curves are available in Supplementary Information Figure S3. 
Figure 3. (a) Schematic of the bisulphite conversion process: Upon bisulphite treatment, unmethylated cytosines are converted to uracil whereas 5-methylcytosines are retained. In the subsequent PCR, uracil is substituted by thymine. Thus, the methylated cytosines are mapped to single base alterations $(\mathrm{C}>\mathrm{T})$ of the amplicons. (b) and (c) show melting curves from methylated (M, red) and unmethylated (U, green) probes targeting KIT methylation (site p1). The melting curves were measured for (b) the hypermethylated cell line EST045 and (c) the unmethylated cell line EST164. Graphs of the first derivative of the melting curves are available in Supplementary Information Figure S3.

Figure 4: (a) Mutation profiling of melanoma cell lines. $\Delta T_{\mathrm{m}}$ measured for $B R A F$ c. $1391 \mathrm{G}>\mathrm{A}$ mutation for the seven investigated EST cell lines. Error bars are one standard deviation $(\mathrm{n}=4-$ 6). The horizontal lines are threshold values used for genotyping: $\Delta T_{\mathrm{m}}<-2{ }^{\circ} \mathrm{C}$ (green) WT, $-2{ }^{\circ} \mathrm{C}<\Delta T_{\mathrm{m}}<2{ }^{\circ} \mathrm{C}$ (yellow) heterozygous $\mathrm{MT}, \Delta T_{\mathrm{m}}>2{ }^{\circ} \mathrm{C}$ (red) homozygous MT. (b) Heat map of $\Delta T_{\mathrm{m}}$ measured for the mutation and for the investigated EST cell lines. (c) Heat map of measured $\Delta T_{\mathrm{m}}$ with applied threshold to genotype mutations: WT in green, heterozygous MT in yellow, homozygous MT in red. 
Figure 5. Mutation and methylation profiling of melanoma cell lines. (a) Heat map of $\Delta T_{\mathrm{m}}$ measured for KIT and RARB methylation probes for the seven investigated EST cell lines. Calculation of $\Delta T_{\mathrm{m}}$ for EST007 KIT was not possible due to low binding signal. (b) $\Delta T_{\mathrm{m}}$ values measured for KIT $\mathrm{p} 1$ (blue squares) and $\mathrm{p} 2$ (orange circles) methylation probe locations vs. methylation density measured by pyrosequencing. (b) $\Delta T_{\mathrm{m}}$ measured for $R A R B \mathrm{p} 1$ (blue squares) and $\mathrm{p} 2$ (orange circles) methylation probe locations vs. methylation level measured by pyrosequencing. Error bars are one standard deviation $(n=4-6)$. 


\title{
ASSOCIATED CONTENT
}

Supporting Information. Table S1, DNA probe sequences. Table S2, PCR primer sequences. Table S3, pyrosequencing primers sequences. Figure S1, $\Delta T_{\mathrm{m}}$ measured for all probes and for all cell-lines. Figure S2, absolute $T_{\mathrm{m}}$ values measured for $N R A S$ c. $182 \mathrm{~A}>\mathrm{T}$ and denaturing gradient gel electrophoresis of $N R A S$ exon2 PCR products. Figure S3, first temperature derivative of melting curves shown in Figures 2-3. Figure S4, pictures of temperature control unit with mounted chip and its mounting in Helmholtz coils for measurements. Figure S5, temperature dependence of center and side tones of GRM sensor. This material is available free of charge via the Internet at http://pubs.acs.org.

\section{AUTHOR INFORMATION \\ Corresponding Author \\ * e-mail: sxwang@stanford.edu \\ *e-mail: Mikkel.Hansen@nanotech.dtu.dk}

\begin{abstract}
Author Contributions
The manuscript was written through contributions of all authors. All authors have given approval to the final version of the manuscript.
\end{abstract}

Funding Sources 
This work was supported by the Danish Council for Independent Research (Postdoc project, DFF-4005-00116), the Autoimmunity Center of Excellence (U19AI110491), and the Center for Cancer Nanotechnology Excellence (U54CA151459 and U54CA199075).

S.X.W. has related patents or patent applications assigned to the Stanford University and outlicensed for potential commercialization. S.X.W. has stock or stock options in MagArray, Inc., which has licensed relevant patents from the Stanford University for commercialization of GMR biosensor chips.

\section{REFERENCES}

(1) Hanahan, D.; Weinberg, R. A. The Hallmarks of Cancer. Cell 2000, 100, 57-70.

(2) Hanahan, D; Weinberg, R. A. Hallmarks of Cancer: The Next Generation. Cell 2011, $144,646-674$.

(3) Esteller, M.; Corn, P. G.; Baylin, S. B.; Herman, J. G. A Gene Hypermethylation Profile of Human Cancer 1. Cancer 2001, 3, 3225-3229.

(4) Baylin, S. B. DNA Methylation and Gene Silencing in Cancer. Nat. Clin. Pract. Oncol. 2005, 2, S4-S11.

(5) Herman, J. G.; Baylin, S. B. Gene Silencing in Cancer in Association with Promoter Hypermethylation. N. Engl. J. Med. 2003, 349, 2042-2054.

(6) Serizawa, R. R.; Ralfkiær, U.; Steven, K.; Lam, G. W.; Schmiedel, S.; Schüz, J.; Hansen, A. B.; Horn, T.; Guldberg, P. Integrated Genetic and Epigenetic Analysis of Bladder Cancer Reveals an Additive Diagnostic Value of FGFR3 Mutations and Hypermethylation Events. Int. J. Cancer 2011, 129, 78-87.

(7) Shen, L.; Toyota, M.; Kondo, Y.; Lin, E.; Zhang, L.; Guo, Y.; Hernandez, N. S.; Chen, X.; 
Ahmed, S.; Konishi, K.; Hamilton, S. R.; Issa, J. J. Integrated Genetic and Epigenetic Analysis Identifies Three Different Subclasses of Colon Cancer. Proc. Natl. Acad. Sci. U.

S. A. 2007, 104, 18654-18659.

(8) Plongthongkum, N.; Diep, D. H.; Zhang, K. Advances in the Profiling of DNA

Modifications: Cytosine Methylation and beyond. Nat. Rev. Genet. 2014, 15, 647-661.

(9) Laird, P. W. Principles and Challenges of Genome-Wide DNA Methylation Analysis. Nat. Rev. Genet. 2010, 11, 191-203.

(10) Orita, M.; Suzuki, Y.; Sekiya, T.; Hayashi ', K. Rapid and Sensitive Detection of Point Mutations and DNA Polymorphisms Using the Polymerase Chain Reaction. Genomics 1989, 5, 874-879.

(11) Saiki, R. K.; Scharf, S.; Faloona, F.; Mullis, K. B.; Horn, G. T.; Erlich, H. A.; Arnheim, N. Enzymatic Amplification of Beta-Globin Genomic Sequences and Restriction Site Analysis for Diagnosis of Sickle Cell Anemia. Science. 1985, 230, 1350-1354.

(12) Wang, D. G.; Fan, J.-B.; Siao, C.-J.; Berno, A.; Young, P.; Sapolsky, R.; Ghandour, G.; Perkins, N.; Winchester, E.; Spencer, J.; Kruglyak, L.; Stein, L.; Hsie, L.; Topaloglou, T.; Hubbell, E.; Robinson, E.; Mittmann, M.; S. Morris, M.; Shen, N.; Kilburn, D.; et al. Large-Scale Identification, Mapping, and Genotyping of Single-Nucleotide Polymorphisms in the Human Genome. Science 1998, 280, 1077-1082.

(13) Orita, M.; Iwahana, H.; Kanazawat, H.; Hayashi, K.; Sekiya, T. Detection of Polymorphisms of Human DNA by Gel Electrophoresis as Single-Strand Conformation Polymorphisms (Mobility Shift of Separated Strands/point Mutation/riction Franment Length Polymorphism). Genetics 1989, 86, 2766-2770.

(14) Metzker, M. L. Sequencing Technologies - the next Generation. Nat. Rev. Genet. 2010, 
$11,31-46$.

(15) Worm, J.; Aggerholm, A.; Guldberg, P. In-Tube DNA Methylation Profiling by

Fluorescence Melting Curve Analysis. Clin. Chem. 2001, 47, 1183-1189.

(16) Wojdacz, T. K.; Dobrovic, A. Methylation-Sensitive High Resolution Melting (MS-

HRM): A New Approach for Sensitive and High-Throughput Assessment of Methylation.

Nucleic Acids Res. 2007, 35, e41-e41.

(17) Xu, L.; Yu, H.; Akhras, M. S.; Han, S. J.; Osterfeld, S.; White, R. L.; Pourmand, N.;

Wang, S. X. Giant Magnetoresistive Biochip for DNA Detection and HPV Genotyping.

Biosens. Bioelectron. 2008, 24, 99-103.

(18) Rizzi, G.; Østerberg, F. W.; Dufva, M.; Fougt Hansen, M. Magnetoresistive Sensor for

Real-Time Single Nucleotide Polymorphism Genotyping. Biosens. Bioelectron. 2014, 52, $445-451$.

(19) Rizzi, G.; Lee, J.-R.; Guldberg, P.; Dufva, M.; Wang, S. X.; Hansen, M. F. Denaturation Strategies for Detection of Double Stranded PCR Products on GMR Magnetic Biosensor Array. Biosens. Bioelectron. 2017, 93, 155-160.

(20) Gaster, R. S.; Hall, D. a; Nielsen, C. H.; Osterfeld, S. J.; Yu, H.; Mach, K. E.; Wilson, R. J.; Murmann, B.; Liao, J. C.; Gambhir, S. S.; Wang, S. X. Matrix-Insensitive Protein Assays Push the Limits of Biosensors in Medicine. Nat. Med. 2009, 15, 1327-1332.

(21) Rizzi, G.; Østerberg, F. W.; Henriksen, A. D.; Dufva, M.; Hansen, M. F. On-Chip Magnetic Bead-Based DNA Melting Curve Analysis Using a Magnetoresistive Sensor. $J$. Magn. Magn. Mater. 2015, 380, 215-220.

(22) Dufva, M.; Petersen, J.; Poulsen, L. Increasing the Specificity and Function of DNA Microarrays by Processing Arrays at Different Stringencies. Anal. Bioanal. Chem. 2009, 
$395,669-677$.

(23) Petersen, J.; Poulsen, L.; Petronis, S.; Birgens, H.; Dufva, M. Use of a Multi-Thermal Washer for DNA Microarrays Simplifies Probe Design and Gives Robust Genotyping Assays. Nucleic Acids Res. 2008, 36, e10.

(24) Fiche, J. B.; Buhot, a; Calemczuk, R.; Livache, T. Temperature Effects on DNA Chip Experiments from Surface Plasmon Resonance Imaging: Isotherms and Melting Curves. Biophys. J. 2007, 92, 935-946.

(25) Wagner, C. E.; Macedo, L. J. A.; Opdahl, A. Temperature Gradient Approach for Rapidly Assessing Sensor Binding Kinetics and Thermodynamics. Anal. Chem. 2015, 87, 78257832.

(26) Hall, D. A.; Gaster, R. S.; Osterfeld, S. J.; Murmann, B.; Wang, S. X. GMR Biosensor Arrays: Correction Techniques for Reproducibility and Enhanced Sensitivity. Biosens. Bioelectron. 2010, 25, 2177-2181.

Dahl, C.; Christensen, C.; Jönsson, G.; Lorentzen, A.; Skjødt, M. L.; Borg, A.; Pawelec, G.; Guldberg, P. Mutual Exclusivity Analysis of Genetic and Epigenetic Drivers in Melanoma Identifies a Link Between p14ARF and RAR $\beta$ Signaling. Mol. Cancer Res. 2013, 11, 1166-1178.

(28) Dahl, C.; Abildgaard, C.; Riber-Hansen, R.; Steiniche, T.; Lade-Keller, J.; Guldberg, P. KIT Is a Frequent Target for Epigenetic Silencing in Cutaneous Melanoma. J. Invest. Dermatol. 2015, 135, 516-524.

(29) DAHL, C.; GULDBERG, P. The Genome and Epigenome of Malignant Melanoma. APMIS 2007, 115, 1161-1176.

(30) Hoon, D. S. B.; Spugnardi, M.; Kuo, C.; Huang, S. K.; Morton, D. L.; Taback, B. 
Profiling Epigenetic Inactivation of Tumor Suppressor Genes in Tumors and Plasma from Cutaneous Melanoma Patients. Oncogene 2004, 23, 4014-4022.

(31) Furuta, J.; Umebayashi, Y.; Miyamoto, K.; Kikuchi, K.; Otsuka, F.; Sugimura, T.;

Ushijima, T. Promoter Methylation Profiling of 30 Genes in Human Malignant Melanoma. Cancer Sci. 2004, 95, 962-968.

(32) Gaster, R. S.; Xu, L.; Han, S.-J.; Wilson, R. J.; Hall, D. a; Osterfeld, S. J.; Yu, H.; Wang, S. X. Quantification of Protein Interactions and Solution Transport Using High-Density GMR Sensor Arrays. Nat. Nanotechnol. 2011, 6, 314-320.

(33) SantaLucia, J. A Unified View of Polymer, Dumbbell, and Oligonucleotide DNA NearestNeighbor Thermodynamics. Proc. Natl. Acad. Sci. U. S. A. 1998, 95, 1460-1465.

(34) Osterfeld, S. J.; Yu, H.; Gaster, R. S.; Caramuta, S.; Xu, L.; Han, S.-J.; Hall, D. a; Wilson, R. J.; Sun, S.; White, R. L.; Davis, R. W.; Pourmand, N.; Wang, S. X. Multiplex Protein Assays Based on Real-Time Magnetic Nanotag Sensing. Proc. Natl. Acad. Sci. U. S. A. 2008, 105, 20637-20640.

(35) Kim, D.; Marchetti, F.; Chen, Z.; Zaric, S.; Wilson, R. J.; Hall, D. A.; Gaster, R. S.; Lee, J.-R.; Wang, J.; Osterfeld, S. J.; Yu, H.; White, R. M.; Blakely, W. F.; Peterson, L. E.; Bhatnagar, S.; Mannion, B.; Tseng, S.; Roth, K.; Coleman, M.; Snijders, A. M. et al. Nanosensor Dosimetry of Mouse Blood Proteins after Exposure to Ionizing Radiation. Sci. Rep. 2013, 3, 1-8.

Hall, D. A.; Gaster, R. S.; Lin, T.; Osterfeld, S. J.; Han, S.; Murmann, B.; Wang, S. X. GMR Biosensor Arrays: A System Perspective. Biosens. Bioelectron. 2010, 25, 20512057. 


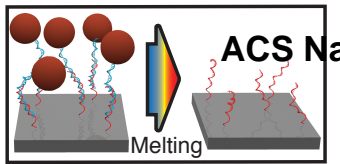

2

3

4

5

6

7

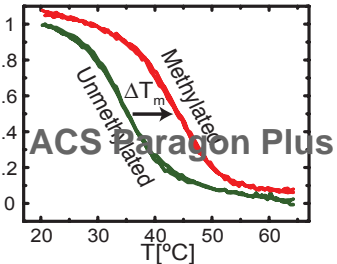

$\infty$
$\stackrel{\infty}{\oplus}$
$\frac{}{0}$
.0

苞

$\Delta \mathrm{T}_{\mathrm{m}}\left[{ }^{\circ} \mathrm{C}\right]$

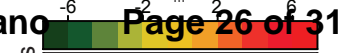

을

Melanoma Cell Lines Mutation and methylation detection 


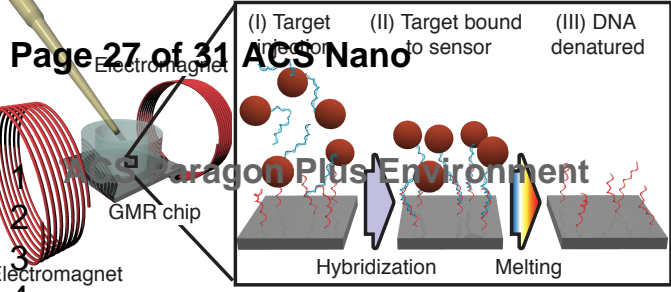




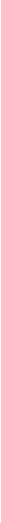

(b) 0

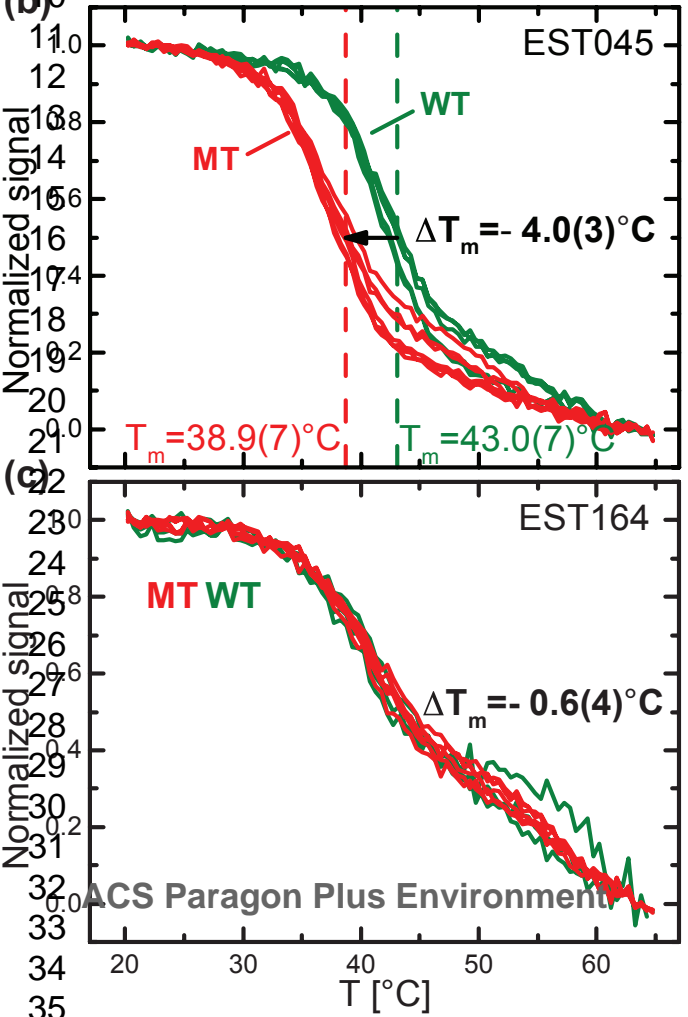


(a)

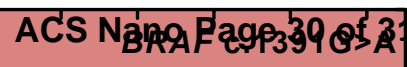

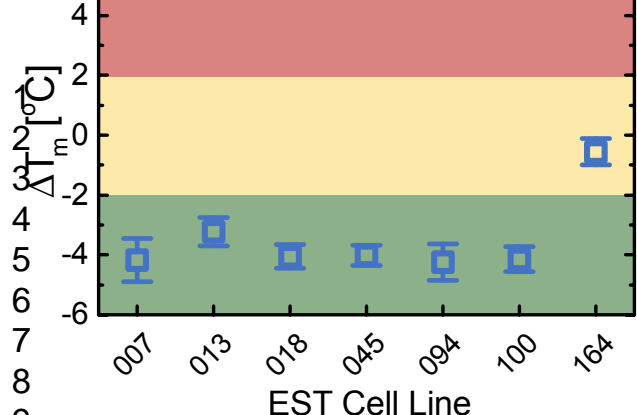

9

EST Cell Line

(b

b) $\frac{4}{\frac{1}{5}}$

c. $1391 \mathrm{G}>\mathrm{A}-$

12

$13^{\text {c. } 1799 T>A-}$

$1 \mathrm{~L} .1798 \mathrm{GT}>\mathrm{AA}$ -

15

œ 16 c. $181 \mathrm{C}>\mathrm{A}$ -

17

(c) 8

c. $182 \mathrm{~A}>\mathrm{T}-$

19 c. $1391 \mathrm{G}>\mathrm{A}$

$\frac{4}{\frac{4}{x}}$

20

p1

c. $1799 \mathrm{~T}>\mathrm{A}$

Е2798GT >AA-

23

s

24

\$5

c.182A $>T-1$

c. $181 \mathrm{C}>\mathrm{A}-$

26 ACS Paragon-Pius Environmemt

27

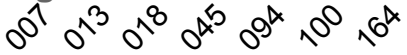

28

EST Cell Line 


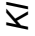

p2

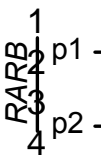

5

6

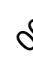

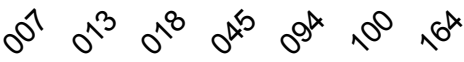

7

\section{EST Cell Line}

(b)

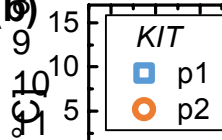

120

$+3-5$ -

1410

1515

(c) 62

171 , 1 RARB

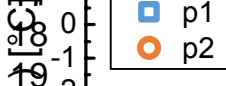

$+9$

20 .

$2 x^{f}-4=$

$22-50$ d $23^{-6} \frac{1}{0} 102030405060$ 24 Methylation density by pyrosequencing (\%) 